\title{
INDICAÇÓES A RESPEITO DA DIVISÃO DAS CIÊNCIAS EM IBN SINA (AVICENA)
}

\author{
Miguel Attie Filho*
}

Resumo: No interior da falsafa, o tema da classificação das ciências foi um dos pontos importantes que marcou a presença das teorias da filosofia e da ciência escritas em árabe na formação do pensamento medieval da Europa, a partir das traduções para o latim, notadamente no séc. XII d.C. O presente artigo apresenta a divisão das ciências de acordo com as informações contidas na Metafisica da AlShifa' e na Epistola sobre as partes das ciências intelectuais de Ibn Sina (Avicena 980-1037 d.C.).

Palavras-chave: Avicena, Ibn Sina, Filosofia em árabe, Falsafa, Filosofia Medieval.

Abstract: Within the falsafa, the subject of the classification of sciences was one of the important points which marked the presence of the theories of Philosophy and Science written in Arabic during the formation of the European medieval thought, through translation into Latin, markedly in the 11th century A.D. This article presents the division of sciences according to information contained in the Metaphysics of Al-Shifa' and in the Epistle on the parts of intellectual sciences by Ibn Sina (Avicena 980-1037 A.D.)

Key words: Avicenna, Ibn Sina, Arabic Philosophy, Falsafah, Medieval Philosophy.

A doutrina do conhecimento de Ibn Sina (980-1037d.C) não deixa de constituir uma cadeia hierárquica ascendente em que cada uma das faculdades da alma cumpre uma etapa precisa nesse processo contínuo que leva do sensível ao inteligível, do material ao imaterial ${ }^{1}$. No topo, encimando os graus ascendentes do conhecimento, está a atualização do intelecto, a mais própria das faculdades da alma humana, cujo aperfeiçoamento só é completado por meio da conexão com a inteligência ativa, uma das dez inteligências cósmicas. Ora, o estudo das inteligências separadas é tema da Ciência Divina - isto é, a metafísica - e, portanto, assim como o intelecto

\footnotetext{
*Professor Doutor de Filosofia e Cultura Árabe do Departamento de Letras Orientais da Faculdade de Filosofia, Letras e Ciências Humanas da Universidade de São Paulo.

1. Cf. Attie Fo, M. O intelecto no Livro da Alma de Ibn Sina (Avicena) Tese de doutorado, FFLCH/USP, São Paulo, 2004.
} 
ocupa o topo das faculdades, a Ciência Divina deve ocupar o topo das ciências. O horizonte no qual se constitui a Ciência Divina está pleno de interligações com as demais ciências, seja para fornecer-lhes os princípios, seja para fundamentar suas finalidades, seja para justificar suas próprias existências. Um breve percurso por algumas passagens de Ibn Sina pode nos dar uma visão panorâmica do conjunto dos saberes.

A própria divisão da $A l$-Shifâ ' - obra que Ibn Sina escreveu já em idade madura, a pedido de um de seus discípulos, Al-Juzjani - fornece uma primeira indicação. Vale lembrar que ele iniciou essa obra em Hamadan e levou aproximadamente dez anos para completá-la em Isfahan, quando tinha por volta de cinqüenta anos, vindo a falecer poucos anos depois. Na ocasião, Al-Juzjani ter-lhe-ia pedido que escrevesse comentários às obras de Aristóteles. Não obstante Ibn Sina seguir de perto a estrutura de classificação da escola peripatética - declarando no prólogo que faria o discurso de acordo com tal estilo - a recusa do comentário e a idéia da reunião dos saberes não deixam de ser fatos notáveis. Herdeiro da tradição peripatética e neoplatônica em língua árabe, sob seu projeto estendeu-se uma concepção própria da classificação das ciências e da possibilidade de realizá-las. Assim, a Al-Shifấ ${ }^{2}$ apresenta-se dividida em quatro tomos, fornecendo uma primeira indicação, ainda que parcial, do modo como Ibn Sina propõe uma divisão das ciências: Lógica, Física, Matemática e Ciência Divina. Nessa ordem constam, além da Lógica, as três partes principais das ciências teóricas. Os livros que as compõem têm por base uma ordenação peripatética, arranjando-se da seguinte maneira: o tomo da Lógica compreende nove capítulos: "Isagoge", "Categorias", "Perihermeneas", "Primeiros analíticos", "Segundos analíticos", "Dialética", "Sofística", "Retórica" e "Poética". A Física compreende oito capítulos: a "Física" propriamente dita, "O céu e o mundo", "A geração e a corrupção", "As ações e as paixões", "Os meteoros", "A alma", "Os vegetais" e "Os animais". A Matemática é disposta em quatro livros: "Geometria", "Aritmética", "Música" e "Astronomia”. E finalmente a Ciência Divina compreende dez capítulos ${ }^{3}$. A explicação de algumas razões que

2. Para mais informações sobre a composição da Al Shifấ, assim como detalhes de vida e obra de Ibn Sina, Cf. ATTIE F., M. Falsafa - a filosofia entre os árabes. São Paulo: Palas Athena, 2002, pp. 226-265.

3. A divisão dos capítulos da Ciência Divina é a seguinte: No Capítulo I, discute-se e estabelece-se o sujeito da filosofia primeira e suas ramificações; inicia-se o estudo da existência pela designação dos existentes, estabelecem-se distinções e multiplicidade entre os existentes possíveis diante da unidade do necessário da existência. O Capítulo II trata da análise da substância e de suas divisões. O Capítulo III trata da natureza e da variedade dos acidentes. O Capítulo IV estuda as relações entre substâncias e acidentes. No Capítulo V encontra-se a análise do universal e do particular e suas intrínsecas relações. O Capítulo VI estuda as quatro causas: agente, final, material e formal. O Capítulo VII dirige-se à refutação de doutrinas antigas, dentre as quais a doutrina das idéias. O Capítulo VIII retorna aos atributos do necessário da existência, agora, com traços 
levaram a essa divisão, de tomos e capítulos, é fornecida pelo próprio Ibn Sina, em seu prólogo:

Iniciei este livro começando pela Lógica e nele procurei seguir a ordenação dos livros do autor da Lógica, indicando alguns segredos e coisas apuradas inexistentes em outros livros. Dei prosseguimento a esta parte com a Física, mas nessa disciplina não acompanhei de perto sua classificação e seu memorial. Segui, então, pela Geometria, resumindo o livro Elementos de Euclides, com um bom resumo, trazendo soluções para ambigüidades, mas sem me prolongar muito. Depois, prossegui com um resumo do mesmo tipo, do livro sobre astronomia, o Almagesto, incluindo, além do resumo, um índice e algumas explicações. Anexei nele, ainda, alguns adendos, terminando-o com o que é necessário para o conhecimento dos aprendizes para dominar a disciplina e fazer correlações entre os princípios da astronomia e as leis naturais. Em seguida, apresentei um bom resumo do livro Introdução à aritmética e concluí a disciplina dos matemáticos com a Música como foi revelada para mim, além de uma pesquisa longa e uma análise minuciosa do resumo. Finalizei o livro com a Ciência que diz respeito à Metafísica segundo suas divisões e seus aspectos, fazendo nele menções à Ciência Ética è à Política, para compor, a partir delas, uma coletânea separada ${ }^{4}$.

Assim justificado, Ibn Sina inclui as ciências Ética e Política entre as ciências práticas, embora elas não constem da divisão em quatro tomos da Al-Shifa', sendo tratadas, timidamente, apenas nos derradeiros capítulos da Divina. A primeira informação que determina as duas áreas - teórica e prática - está já no correr do texto e pode ser lida nesta passagem:

As ciências filosóficas, como já foi assinalado, nos livros, em outros lugares, dividem-se em teóricas e práticas ${ }^{5}$.

Tal distinção é fundamental para ordenar e classificar as ciências nas duas direções apontadas segundo um critério de princípios de ação. Assim, as ciências teóricas são aquelas nas quais se busca o aperfeiçoamento da faculdade teórica da alma por meio da atualização do intelecto: seu propósito é a aquisição de um conhecimento certo das coisas cuja existência não depende da ação humana. Seu resultado é, portanto, uma simples concepção, um certo ponto de vista ou uma certa convicção, sem que tais resultados sejam princípios de ações ou que, a partir deles, ocorra necessariamente qualquer tipo de ação. Por outro lado, as ciências práticas

\footnotetext{
neoplatônicos em que este é definido por ser inteligência, inteligente e inteligido. O Capítulo IX mostra como as dez inteligências derivam do necessário da existência, com suas respectivas almas e corpos celestes, até a processão do mundo sublunar, no qual há composição de matéria e forma. Esse capítulo inicia, ainda, a questão do retorno das almas humanas e trata também da questão do mal. O Capítulo X continua tratando da questão do retorno e, ao final, há considerações éticas e políticas a respeito da sociedade dos homens.

4. Al-Shifấ, Introdução.

5. AVICENNE, La métaphysique du Shifa. Traduction G. Anawati. Paris: J. Vrin, 1985, p. 85.
} 
são aquelas a partir das quais se busca o aperfeiçoamento da faculdade teórica para que o resultado seja um princípio de ação, ou a efetivação propriamente de uma ação. Seu propósito não é a aquisição apenas de uma concepção, mas de uma concepção em vista de uma ação que vise o bem e o justo. A divisão das ciências acompanha a divisão das operações da alma. Veja-se nesta passagem:

É como se nossa alma possuísse duas faces: uma em direção ao corpo - mas é preciso que esta face não receba de modo algum uma impressão de um gênero exigido pela natureza do corpo - e uma face em direção aos princípios supremos - mas é preciso que esta face receba constantemente daquilo que lá está e sofra o seu efeito. Assim, do lado inferior nascem os hábitos morais e do lado superior nascem as ciências ${ }^{6}$.

Nesta outra afirma-se que a primeira dirige-se à verdade e a segunda dirige-se ao bem:

Assim, a primeira faculdade que a alma humana possui é uma faculdade que se refere à análise e chama-se intelecto teórico. E uma segunda faculdade que se refere à prática e chama-se intelecto prático. Aquela é para a verdade e para a falsidade, enquanto esta é para o bem e para o mal nos particulares ${ }^{7}$.

Aceita e justificada essa primeira distinção, poder-se-ia esperar que Ibn Sina ordenasse as disciplinas envolvidas em cada uma delas, mas ele não o faz. Uma ordenação completa, que está de acordo com a divisão do início da Divina, pode ser encontrada na Epístola sobre as divisões das ciências intelectuais ${ }^{8}$, a mapear as disciplinas que fazem parte de cada um dos dois ramos. Na Epístola, as partes do saber teórico - al-hikmat al-nazaryia ${ }^{9}$ - também são definidas em número de três, mas o são de modo hierárquico:

6. AVICENNA, De Anima, op. cit., p. 47 “ (...) tamquam anima nostra habeat duas facies, faciem silicet deorsum ad corpus, quam oportet nullatenus recipere aliquam affectionem generis debiti naturae corporis, et alliam faciem sursum, versus principia altissima, quam oportet semper recipere aliquid ab eo quod est illic et affici ab illo. Ex eo autem quod est infra eam, generantur mores, sed ex eo quod est supra eam, generantur sapientiae;(...)" AVICENNA LATINUS, Liber de anima, op. cit., p.94.

7. AVICENNA, De Anima. Arabic texte edited by F. Rahman. London University Press, 1959, p. 207 "Ergo prima virtus humanae animae est virtus quae comparatur contemplationi et vocatur intellectus contemplativus, qui est iudex veri et falsi de universalibus; haec autem virtus activa est de bono et malo in particularibus." CF.AVICENNA LATINUS, Liber de anima IV-V. Édition critique par S. Van Riet. Louvain: Brill, 1968, p. $77 \mathrm{~s}$.

8. Rabia Mimoune publicou uma tradução francesa com o título "Épître sur les parties des sciences intellectuelles" em VVAA, Études sur Avicenne, Paris: Les Belles Lettres, 1984, pp. 143-151. Ibn Sina aborda o tema da classificação das ciências em outras obras, inclusive na parte da Lógica da Al-Shifấ'.

9. Cf. "Épître”,. p.144. 
As partes do saber teórico são três: a ciência inferior, chamada Física; a ciência intermediária chamada Ciência Matemática e a ciência superior que se chama Ciência Divina $^{10}$.

Os ramos da Física são indicados a partir do critério de princípio, desdobrandose depois em subdivisões. A divisão em ramos, a partir dos princípios, ainda que em outra ordem, corresponde aos oito livros da parte da Física da Al-Shifâ ' que assinalamos no início deste nosso artigo. As partes secundárias da Física, desbordantes do quadro aristotélico, são indicadas logo a seguir, em número de sete: Medicina, Astrologia, Fisiognomia, Oniromancia, Ciência dos talismans, Teurgia e Alquimia ${ }^{11}$.

No caso das ciências intermediárias, isto é, a Matemática, a Epistola repete as quatro partes que mencionamos: Aritmética, Geometria, Astronomia e Música. Ibn Sina confirma o que dissera no prólogo da Al-Shifâ': a Geometria está contida no livro de Euclides, Elementos, e a Astronomia, no livro de Ptolomeu, Almagesto. As partes secundárias incluem uma série de outros saberes: na parte da Aritmética está contida, por exemplo, a álgebra, o cálculo indiano e a muqâbala. ${ }^{12} \mathrm{Na}$ Geometria encontram-se as ciências da medição, da tração, dos pesos, dos espelhos e a hidráulica. Na Astronomia encontra-se a ciência das tábuas astronômicas e a dos calendários. No caso da Música, inclui-se a arte do manejo dos instrumentos. Esse é, portanto, o quadro completo das ciências teóricas, a partir da Epístola, em harmonia com a divisão indicativa proposta no Capítulo I da Divina.

Quanto às ciências práticas, o critério de determinação de suas partes é a associação humana, a partir de três níveis distintos. A primeira ciência refere-se à conduta individual do homem, naquilo que dirige seus hábitos e suas ações. Ibn Sina afirma que esta é a ciência Ética e encontra-se na Ética de Aristóteles. A segunda é a ciência que resulta da associação doméstica dos homens, quanto à regulação, administração dos bens e cuidado com seus dependentes, para possibilitar-lhes a busca da felicidade. Tal é a ciência da Economia, e encontra-se na Economia de Aristóteles. O terceiro nível diz respeito à associação humana em seu conjunto, isto é, a organização da comunidade, das cidades, etc. Ibn Sina afirma que essa é a ciência Política e encontra-se nas Leis e em outras obras de Platão e de Aristóteles ${ }^{13}$. A passagem é a seguinte: "aquilo que concerne ao poder está exposto

$\overline{\text { 10. Cf. ibid,. p.144. }}$

11. Ibid, p.146. Não nos deteremos a discutir os casos de cada uma das ciências apontadas. Na Epístola, Ibn Sina fornece algumas breves indicações a esse respeito.

12. Acompanhamos a tradução francesa de Mimoune, na qual o termo aparece transliterado. Cf. "Épître”,. p. 147.

13. ibid, p. 85 texto árabe e p.145 trad. francesa. 
nos livros de Platão e de Aristóteles a respeito da Política”. Há uma variação de manuscritos, em que se encontra a referência somente "ao livro de Platão" e não "aos livros de Platão". A sequência da passagem traz especificamente as Leis, mas isso não garante que a referência fosse apenas a essa obra. O conteúdo da era conhecido entre os árabes. No caso da referência a Aristóteles, o problema é de outra natureza. Os manuscritos não variam na construção da frase. No entanto, o sentido é dúbio, na medida em que não fica claro se a referência é ao livro Política ou ao tema da política. De todo modo, ainda que seja somente ao tema, é possível entender que Ibn Sina sabia de uma obra de Aristóteles a esse respeito, ainda que ela não tivesse chegado às suas mãos. A passagem é importante parte da discussão que envolve a tradução da Política para a língua árabe, naquele período.

De todo modo, partindo das informações da Divina, completadas com as da Epístola - excetuando-se os ramos da Divina e o caso da Lógica, teríamos, até este ponto, o seguinte quadro da classificação das ciências:

\section{Ciências teóricas}

\begin{tabular}{|c|c|c|c|c|}
\hline Ciência superior & \multicolumn{4}{|c|}{ DIVINA } \\
\hline $\begin{array}{c}\text { Ciência } \\
\text { intermediária }\end{array}$ & \multicolumn{4}{|c|}{ MATEMÁTICA } \\
\hline Quatro ramos & Aritmética & Geometria & Música & Astronomia \\
\hline Subdivisões & $\begin{array}{l}\text { Cálculo Indiano } \\
\text { Álgebra } \\
\text { Muqâbala }\end{array}$ & $\begin{array}{l}\text { Medidas } \\
\text { Engenhosidade } \\
\text { Tração } \\
\text { Pesos } \\
\text { Máquinas } \\
\text { Espelhos } \\
\text { Hidráulica }\end{array}$ & $\begin{array}{l}\text { Execução de } \\
\text { instrumentos }\end{array}$ & $\begin{array}{l}\text { Tábuas as- } \\
\text { tronômicas } \\
\text { Calendários }\end{array}$ \\
\hline
\end{tabular}

\begin{tabular}{|c|c|c|c|c|}
\hline \multirow{2}{*}{ Ciência inferior } & \multicolumn{4}{|c|}{ FÍSICA } \\
\hline \multirow{2}{*}{ Oito Ramos } & A Física & O Céu e o Mundo & $\begin{array}{c}\text { A Geração e a } \\
\text { Corrupção }\end{array}$ & Os Meteoros \\
\cline { 2 - 5 } & Os Minerais & A Alma & Os Vegetais & Os Animais \\
\hline \multirow{2}{*}{ Subdivisões } & Medicina & Astrologia & Fisiognomia & Oniromancia \\
\cline { 2 - 5 } & Talismans & Teurgia & Alquimia & \\
\hline
\end{tabular}

\section{Ciências práticas}

\begin{tabular}{|c|c|c|c|}
\hline Três ramos & Ética & Economia & Política \\
\hline
\end{tabular}




\section{Bibliografia:}

ATTIE F ${ }^{\circ}$, M. O intelecto no Livro da Alma de Ibn Sina (Avicena). Tese de doutorado, FFLCH, USP, 2004.

Falsafa, A filosofia entre os árabes. São Paulo: Palas Athena, 2002.

AVICENNE, La métaphysique du Shifa. Traduction G. Anawati. Paris: J. Vrin, 1985.

VVAA, Études sur Avicenne, "Êpitre sur les parties des sciences intellectuelles”. Paris: Les Belles Letres, 1984. 